\title{
Movimentos sociais e participação em contexto de conflitos socioambientais: uma proposta de matriz de análise.
}

\section{Movimientos sociales y participación en contexto de conflictos ambientales: una propuesta de matriz de análisis.}

\section{Social movements and participation in contexts of environmental conflicts: proposal for an analytical matrix.}

Maria da Graça Luderitz Hoefe ${ }^{1}$ Denise Osório Severo ${ }^{2}$

RESUMO: As formas de participação e atuação dos movimentos sociais vêm passando por profundas alterações nas últimas décadas e têm acompanhado as mudanças estruturais e conjunturais da sociedade. No contexto do Brasil e do mundo, o reascenso de grandes mobilizações e demandas pela democracia evidenciam que as lutas sociais, políticas e culturais têm apresentado novos contornos, estratégias e formas de organização que necessitam reflexão. Nesse sentido, a participação social em saúde também tem transitado e seguido o fluxo da dinâmica social, revelando cada vez mais suas interfaces com o ambiente, com o modelo de desenvolvimento e com a organização da sociedade. O objetivo deste artigo é discutir uma proposta de Matriz de Análise da intensidade democrática da participação e atuação dos movimentos sociais - à luz do conceito de intensidade democrática de Boaventura de Sousa Santos - bem como debater o seu processo de construção teórica, metodológica e sua aplicabilidade. Esta matriz vem sendo construída desde 2010 (Hoefel et al, 2010) e surge primeiramente vinculada a uma pesquisa sobre as formas de participação social em saúde-trabalho-ambiente no contexto da América Latina. Posteriormente, ela é reformulada, originando uma segunda versão (Hoefel et al, 2011), construída durante o desenvolvimento de uma pesquisa realizada na região da Chapada do Apodi, estado do Ceará, cujo objetivo geral foi analisar os processos de resistência (participação) e violência no contexto de conflitos socioambientais. Os resultados sugerem que a matriz avança no sentido de expressar, em seu conjunto de categorias, o referencial adotado, sinalizando potencialidades e aplicabilidade no que tange à análise da intensidade democrática da participação e à atuação dos movimentos sociais.

1 Doutora em Sociologia. Professora do Departamento de Saúde Coletiva da Universidade de Brasília. Coordenadora do Laboratório de Saúde do Trabalhador e Saúde Indígena/UnB.

2 Doutoranda em Ciências da Saúde/Área de Saúde Coletiva da Universidade de Brasília. Pesquisadora do Laboratório de Saúde do Trabalhador e Saúde Indígena/UnB. 
Palavras-chave: Matriz de análise. Movimentos sociais. Participação social. Saúde. Ambiente.

RESUMEN: Las formas de participación y de acción de los movimientos sociales han experimentado profundos cambios en las últimas décadas y han seguido los cambios estructurales y coyunturales de la sociedad. En Brasil y en el mundo las grandes manifestaciones y demandas por la democracia volvieron a surgir, lo que demuestra que las luchas sociales, políticas y culturales han presentado nuevos esquemas de estrategias y formas de organización que requieren reflexión. En este sentido, la participación social en la salud también se ha trasladado y seguido el flujo de la dinámica social, revelando interfaces cada vez más grandes con el medio ambiente, el modelo de desarrollo y la organización de la sociedad. El propósito de este artículo es discutir una propuesta de Matriz de Análisis de la participación y la intensidad de la acción de los movimientos sociales democráticos - a la luz del concepto de intensidad democrática de Boaventura Sousa Santos. También se analiza el proceso de construcción teórica, metodológica y su aplicabilidad. Esta matriz se ha construido desde el año 2010 (Hoefel et al, 2010) y se presenta sobre todo ligada a la investigación sobre las formas de participación social en salud-trabajo-medio ambiente en el contexto de América Latina. Más tarde, fue reformulada en una segunda versión (Hoefel et al, 2011), construida durante el desarrollo de una encuesta realizada en la Chapada do Apodi, región de Ceará, cuyo objetivo general fue analizar los procesos de resistencia (participación) y la violencia en el contexto de conflictos ambientales. Los resultados sugieren que la matriz avanza en el sentido de expresar, en su conjunto de categorías, el referencial adoptado, señalando su potencial y su aplicabilidad en relación al análisis de la intensidad democrática de la acción y de la participación política de los movimientos sociales. Palabras clave: Matriz de análisis. Movimientos sociales. La participación social. Salud. Medio ambiente

ABSTRACT : Forms of participation and engagement of social movements have been undergoing profound changes in recent decades, and have followed the structural and cyclical changes in society. In Brazil and around the world, the resurgence of large mobilizations and demands for democracy show that social, political and cultural struggles have presented new outline strategies and organizational forms that require reflection. In this sense, social participation in health has also followed the flow of social dynamics and reveals interfaces with the environment, the models of development and the organization of society. The purpose of this paper is to discuss a proposal for matrix of analysis of democratic participation and intensity of social movements' actions - in the light of the Boaventura Sousa Santos' concept of democratic intensity. This paper also discusses the process of theoretical and methodological construction, as well as the applicability of this matrix of analysis. This matrix is built since 2010 (Hoefel et al, 2010) and arises primarily linked to research on forms of social participation in health, work and environment in the context of Latin America. It is later reformulated into a second version (Hoefel et al, 2011), built during the development of a survey conducted in the Chapada do Apodi, Ceará region, whose overall objective was to analyze the processes of resistance (participation) and violence in the context of environmental conflicts. The results suggest that the matrix expresses categories of the adopted framework, signaling its potential and its applicability 
regarding the analysis of democratic participation and intensity of social movements' action. Palavras-chave: Matrix analysis. Social movements. Social participation.Health. Environment.

\section{INTRODUÇÃO}

Neste trabalho, entende-se que a participação social é constituída tanto pela participação instituída, especificamente relacionada às esferas institucionalizadas de participação social, representadas no contexto da sociedade brasileira pelos espaços denominados de "controle social", como pela participação social instituinte, ou seja, a participação desenvolvida no âmbito do conjunto dos movimentos sociais, sejam quais forem suas formas de expressão.

Nesse sentido, os movimentos sociais são concebidos conforme proposto por Gohn ${ }^{1}$, ou seja, como expressões das ações coletivas que traduzem lutas sociais, econômicas ou culturais. Desse modo, os movimentos e as novas formas de expressão da participação social traduzem as permanentes disputas e alianças entre as distintas frações sociais existentes no interior da sociedade civil e expressam o modo como a sociedade se organiza em cada período histórico.

Com efeito, no decorrer do século $\mathrm{XX}$, os movimentos sociais transitaram por momentos de maior ou menor articulação, dependendo da conjuntura econômica e política de cada país. Assim, a observação histórica revela um câmbio nas formas de expressão da sociedade civil produzido no próprio desenvolvimento dos processos de luta e que acompanhou as transformações macroestruturais da sociedade.

Após a segunda metade do século XX, entre os anos 70 e a década de 90, é possível perceber a transição dos movimentos sociais em seu caráter, objetivos e estratégias de atuação. Do mesmo modo que o sistema passou por diferentes períodos de acumulação e crises, os movimentos sociais transitaram de uma postura clássica, pautada na luta por alterações estruturais e traduzida em estratégias de mobilização de massa - com cunho reivindicatório e opositor ao Estado -, para uma característica policlassista e propositiva, voltada à luta por cidadania, porém focalizada e traduzida em manifestações mais pontuais ${ }^{1-6}$.

Desse modo, os esforços realizados na última década do século XX parecem ter sido canalizados para a superação da democracia representativa e a construção de novos espaços e mecanismos direcionados à construção da democracia participativa. Embora esse período tenha sido marcado pela consolidação de políticas neoliberais e pela subtração de uma série de direitos sociais dos cidadãos em todo conjunto da América Latina, é também nesse contexto que, paradoxalmente, emergem diferentes formas de participação e expressão das organizações coletivas da sociedade.

Os anos 90 deflagraram o surgimento de novos atores sociais envolvidos em distintas formas de participação e na construção de novas estratégias e de espaços de manifestação social. Buscou- 
se ampliar a luta anticapitalista na região com a emergência de novos atores sociais, até então distantes dos processos de participação. Nesse processo, a luta social tornou-se mais complexa, como resultado das mudanças na organização produtiva, social e cultural e concorreu para a construção de formas alternativas antineoliberais de participação social no final do século passado ${ }^{7}$.

Nesse sentido, cabe ressaltar a ascensão das redes sociais ${ }^{3}$ como mecanismos de participação, que se fortaleceram ao longo desta década e traduziram uma das importantes formas de expressão que viriam a se consolidar no início dos anos 2000. Assim, o início do século XXI parece refletir as características da dita contemporaneidade, em que as fronteiras entre o novo e o velho perdem a nitidez e as manifestações traduzem a complexidade e a multiplicidade das formas de expressão e de construção das relações sociais e humanas ${ }^{6}$.

Dessa forma, os movimentos e grupos sociais organizados expressam-se, na primeira década do século XXI, por meio de manifestações que revelam tanto características das lutas dos anos 70 e 80, como expressam elementos dos anos 90, como o caráter policlassista, a contestação ao modelo neoliberal adotado e as lutas menos vinculadas às alterações estruturais e mais voltadas ao direito e às diversidades culturais, políticas e sociais, bem como a luta pelo exercício da cidadania ${ }^{1-6}$. Com efeito, no contexto latinoamericano, o início dos anos 2000 caracterizou-se pela emergência de movimentos campesinos e indígenas na Bolívia, Equador, México, Brasil e Argentina, em um cenário de ascensão de governos progressistas em diversos países da América Latina.

É importante ressaltar que o início da segunda década do século XXI evidencia a complexidade cada vez maior das formas de participação dos movimentos, que por sua vez parecem revelar as transições globais decorrentes do estágio atual do capitalismo e dos modelos de desenvolvimento adotados. O reascenso de grandes mobilizações - neste momento articuladas expressivamente pelas redes sociais - deflagradas pela Primavera Árabe a partir de 2011, seguida pelos Movimentos dos Indignados na Espanha, Grécia e Portugal, pelo Movimento Occupy Wall Street nos Estados Unidos, pelos manifestos estudantis no Chile e, mais recentemente, pelas manifestações que eclodiram em junho de 2013 no Brasil sinalizam nesse sentido.

Embora distintas, essas mobilizações traduzem a multiplicidade de formas de participação social atualmente existentes e, ao mesmo tempo, reiteram a importância de refletir sobre todas elas, a fim de poder construir estratégias políticas que favoreçam a ampliação da participação social e o aprofundamento dos processos democráticos.

3 Para Scherer-Warren (2005) as redes sociais caracterizam-se por redes de movimentos sociais que buscam articular atores sociais e culturais, norteadas pela solidariedade e por princípios éticos comuns, cujas lutas são vinculadas às questões mais universais, relacionadas às lutas mundiais pela paz, pelo compromisso ético-político mundial em defesa da vida, contra a pobreza e a miséria e pelo respeito à dignidade humana, adquirindo um caráter cada vez mais transnacional. Referindo-se às Redes Sociais, Lumnitz (2009, p.18) pondera que: "Uma rede social é um campo de relações entre indivíduos que pode ser definido por uma variável predeterminada e se referir a qualquer aspecto de uma relação. Uma rede social não é um grupo bem definido e limitado, senão uma abstração científica que se usa para facilitar a descrição de um conjunto de relações complexas em um espaço social dado. Cada pessoa é o centro de uma rede de solidariedade e, ao mesmo tempo, é parte de outras redes". 
Nesse sentido, compreender as formas de participação social, sejam estas em saúde-trabalhoambiente ou ainda em demais âmbitos relacionados, bem como entender o modo como a sociedade civil está construindo políticas públicas e criando espaços democráticos de vocalização, debate e luta por direitos de cidadania, exige a adoção de parâmetros e categorias que permitam identificálas e analisá-las.

Isso posto, o objetivo deste artigo é discutir uma proposta de Matriz de Análise da intensidade democrática da participação e atuação dos movimentos sociais - à luz do conceito de intensidade democrática de Boaventura Sousa Santos - bem como debater o seu processo de construção teórica, metodológica e sua aplicabilidade. Esta matriz vem sendo construída desde $2010^{7}$ e surge primeiramente vinculada a uma pesquisa sobre as formas de participação social em saúde-trabalhoambiente no contexto da América Latina. Posteriormente ela é reformulada, durante a realização de uma pesquisa sobre os processos de resistência e violência no contexto dos conflitos socioambientais da Chapada do Apodi/Ceará. Tendo em vista o propósito deste artigo, inicialmente apresenta-se a metodologia e, a seguir, discorre-se sobre o processo de construção e a discussão teórica proposta.

\section{METODOLOGIA}

Trata-se de um artigo que discute o processo de construção de uma Matriz de Análise ${ }^{7,8}$ da participação social, cuja primeira versão foi elaborada no contexto de uma pesquisa documental, que realizou mapeamento e análise das experiências de participação social latinoamericanas relacionadas a saúde-trabalho-ambiente, à luz do referencial teórico da abordagem ecossistêmica, inspirados nos apontamentos de Gómez e Minayo ${ }^{9}$. Esse estudo, lócus da primeira versão da Matriz, analisou 76 documentos, com recorte histórico entre 1990 e 2010, constituídos por três tipos: a) artigos científicos oriundos da base CAPES; b) documentos não indexados sobre movimentos sociais no contexto argentino; c) artigos científicos produzidos na Colômbia.

$\mathrm{Na}$ referida pesquisa foram incorporados 04 critérios de inclusão: 1) adoção de 04 palavraschave - Ecosalud, medio ambiente, salud-trabajo-ambiente, participación social; 2) utilização de 43 combinações de palavras-chave; 3) adoção de 05 base de dados: Lilacs, Scielo, PAHO, Medline, Jstore e 4) definição dos idiomas das publicações incluídas: espanhol, português e inglês. A análise dos dados foi realizada por meio da aplicação da Matriz de Análise ${ }^{7}$ construída no processo e objeto deste artigo.

Por outro lado, a segunda versão da Matriz foi construída durante o desenvolvimento de uma pesquisa-ação - a qual previa a realização de uma etapa documental - realizada na região da Chapada do Apodi, estado do Ceará, cujo objetivo geral foi analisar os processos de resistência (participação) e violência no contexto de conflitos socioambientais. Este estudo propiciou o aprofundamento da Matriz anteriormente adotada e significou uma experiência distinta, uma vez que alterou o marco teórico adotado, incorporando o referencial de Boaventura de Sousa Santos, especialmente as concepções de intensidade democrática e ecologia dos saberes ${ }^{10,11}$, buscando materializá-los em 
uma proposta metodologicamente aplicável.

A Matriz foi adotada para análise de 217 documentos, previamente catalogados da seguinte forma: a) Abaixo-assinados; b) Cartas e Ofícios; c) Convites e Programação de Reunião; d) Planos, Projetos e Propostas; e) Relatórios de Reunião; f) Reportagens; g) Requerimentos; h) Diversos. Os documentos apresentam recorte histórico entre 2008 e 2010 e são advindos do acervo do Grupo de Pesquisa Tramas - vinculado à Universidade Federal do Ceará (UFC) - e demais 07 fontes de dados, advindas especialmente dos movimentos sociais, meios de comunicação locais e alguns órgãos governamentais.

\section{Processo de construção da Matriz de Análise - Primeira Versão}

Conforme relatado, a construção da Matriz de Análise ${ }^{7}$ inicia-se em 2010, com a participação de diversos pesquisadores vinculados aos movimentos sociais em saúde-trabalho-ambiente, de sete distintos países da América Latina. Naquela ocasião, buscava-se desenvolver uma pesquisa que pudesse mapear e analisar, inicialmente por meio documental, o cenário das experiências de participação social em saúde-trabalho-ambiente no contexto latino-americano, a partir da abordagem ecossistêmica (ecosalud).

Nesse sentido, Minayo ${ }^{12}$ refere no início do capítulo "Enfoque ecossistêmico da saúde e qualidade de vida", no livro Saúde e Ambiente Sustentável, a maneira como concebe o enfoque, ao afirmar que ele constitui uma das possibilidades de criação teórico-práticas que relacionam a saúde e o ambiente em níveis micro sociais, dialeticamente articulados a uma visão ampla dos dois elementos. De acordo com Gómez e Minayo ${ }^{9}$, existem três pilares no enfoque ecossistêmico de saúde: transdisciplinaridade, participação social e equidade de gênero. Além da categoria gênero, esses autores ressaltam que as categorias classe social, idade, etnia e religião são também importantes no enfoque ecossistêmico de saúde, uma vez que essas características distinguem as pessoas em um grupo social, podendo ser facilitadoras ou dificultadoras quando da implementação de "ações que exigem vários olhares e diversas perspectivas".

Com base neste referencial, a pesquisa foi intitulada: "Políticas, Participación Social y Actores Sociales". Almejava-se contribuir para os processos de reflexão e construção de estratégias políticas de fortalecimento da participação a partir do compartilhamento das experiências encontradas, buscando construir espaços de trocas de saberes entre os movimentos sociais. Para tanto, a segunda etapa do estudo previa a realização de ações de resgate de memória e produção teórica no âmbito dos movimentos, a partir do olhar dos próprios sujeitos e das demandas e saberes dos próprios grupos, com base na educação popular.

Assim, levando em conta que o grupo envolvido nesta pesquisa considerava que o referencial da ecosalud necessitava de aportes no sentido de aprofundamento do eixo da participação social, optouse por construir uma matriz de análise que desse conta do objeto de estudo proposto. Desse modo, 
a partir de uma ampla revisão teórica no campo da análise dos movimentos sociais e participação, foram identificados alguns critérios como elementos reveladores das formas de expressão e das características da participação social, inspirados principalmente em autores como Gohn ${ }^{13}$, ShererWarren ${ }^{4}$, Mirza ${ }^{14}$ e Izaguirre ${ }^{15}$.

Além disso, as experiências de militância política dos membros do estudo também foram levadas em consideração na definição das categorias que viriam a compor a primeira versão da matriz. Havia consenso quanto à importância de compreender o contexto histórico de origem dos movimentos e experiências identificados, as formas de organização, os objetivos, as características das lutas, bem como as estratégias e mecanismos de luta empreendidos. Assim, foram então definidas as categorias que se encontram sintetizadas no quadro abaixo:

Tabela 1. Eixo Participação Social - Categorias da Matriz de Análise da Participação Social ${ }^{7}$ na perspectiva da ecosalud

\section{EIXO PARTICIPACIÓN SOCIAL - CATEGORIAS DA MATRÍZ DE ANÁLISIS DESDE LA PERSPECTIVA DE ECOSALUD}

\begin{tabular}{|l|l|l|l|l|}
\hline $\begin{array}{l}\text { Contexto } \\
\text { histórico } \\
\text { de origen y } \\
\text { evolución } \\
\text { reciente: }\end{array}$ & $\begin{array}{l}\text { Formas de organización/ } \\
\text { participación }\end{array}$ & $\begin{array}{l}\text { Objetivos (banderas } \\
\text { de lucha): }\end{array}$ & $\begin{array}{l}\text { Características de la } \\
\text { participación/lucha } \\
\text { social: }\end{array}$ & $\begin{array}{l}\text { Estrategias de lucha/ } \\
\text { acción social }\end{array}$ \\
\hline Describir: & $\begin{array}{l}\text { Movimientos sociales } \\
\text { Redes sociales } \\
\text { Sindicatos } \\
\text { Centrales sindicales } \\
\text { Foros } \\
\text { Consejos de gestión y } \\
\text { políticas públicas } \\
\text { Asociaciones de barrio } \\
\text { Grupos sociales } \\
\text { específicos } \\
\text { Otros }\end{array}$ & $\begin{array}{l}\text { Alteraciones } \\
\text { estructurales } \\
\text { Alteraciones } \\
\text { coyunturales }\end{array}$ & $\begin{array}{l}\text { Reinvindicatoria } \\
\text { Propositiva } \\
\text { Afirmativa }\end{array}$ & Descripción: \\
\hline & & $\begin{array}{l}\text { Descripción de las } \\
\text { banderas de lucha: }\end{array}$ & & \\
\hline
\end{tabular}

A primeira categoria, intitulada "Contexto histórico de origem e evolução recente", buscava compreender o processo histórico de cada uma das formas de expressão e experiências da participação identificadas nas pesquisas e descrever os movimentos/organizações/experiências para que, a partir da compreensão das origens e evolução dessas manifestações/experiências, fosse possível encontrar elementos que explicassem suas características atuais e pregressas, bem como a importância que representam no interior da sociedade na qual estão incluídas ${ }^{7}$.

A segunda categoria - "Formas de organização/participação" - era considerada fundamental por evidenciar o modo como a participação social se organizava na conjuntura presente, oferecendo 
a possibilidade de identificar os atores sociais envolvidos e subsidiar a comparação entre as formas organizativas mais frequentes nos diferentes países da América Latina. Durante o processo de construção, foram definidas as seguintes subcategorias: Movimentos Sociais, Redes Sociais, Sindicatos, Centrais Sindicais, Fóruns, Conselhos de Gestão e Políticas Públicas, Associações de Bairro, Grupos Sociais Específicos e Outros?

A terceira categoria foi denominada “Objetivos (bandeiras de luta)". Entendia-se que os objetivos dos movimentos e/ou formas de expressão da participação social expressavam as bandeiras de luta dessas organizações e tinham a capacidade de revelar sua identificação com dois tipos de lutas que vieram a compor as subcategorias: a) lutas estruturais e b) lutas conjunturais. A primeira estaria relacionada às lutas por mudanças no modelo de organização da sociedade e, portanto, no modo de produção capitalista. Quanto à segunda, entendia-se que poderia apresentar compromisso com lutas mais relacionadas à conjuntura e, como tal, vinculadas às lutas pela igualdade de direitos ${ }^{15}$.

A quarta categoria, "Características da participação/Luta social", buscava revelar o tipo de participação social desenvolvido em cada uma das formas de expressão (movimentos sociais, redes sociais, fóruns, etc.) encontradas, pois se entendia que cada uma delas expressa características distintas que revelam, em última instância, o âmbito das lutas travadas, a concepção e a forma de relação do movimento/organização com o Estado. Foram adotadas três subcategorias: a) reivindicatória; b) propositiva; c) afirmativa ${ }^{7}$.

De acordo com Gohn² e Carvalho ${ }^{5}$, as lutas reivindicativas estão mais vinculadas à contestação e referem-se às lutas por acesso a bens e serviços de responsabilidade do Estado. Conforme anteriormente mencionado, elas refletem um tipo de participação típico da década de 70 , cuja característica dos movimentos sociais era a luta "de costas para o Estado", considerado por eles como inimigo.

Com relação às lutas propositivas, referem-se às lutas pela ocupação de espaços dentro da arena estatal, pela participação nos processos decisórios das políticas públicas. Esse tipo de participação, de acordo com Carvalho ${ }^{5}$, emerge nos anos 80 e consolida-se nos anos 90, refletindo assim uma nova concepção de sociedade civil e Estado e vinculando a participação a uma perspectiva ampliada do exercício da cidadania.

Nesse sentido, autores como Quevedo e Iokoi ${ }^{16}$, Scherer-Warren ${ }^{4}$ e Gohn ${ }^{2,3}$ também destacam que os movimentos sociais no final dos anos 80 e, especialmente, na década 90, assumem outra postura de luta, passando a valorizar a participação na deliberação das políticas, ampliando sua composição com outros segmentos sociais e priorizando o controle social do Estado. No entanto, com relação às lutas afirmativas, são entendidas como lutas vinculadas ao reconhecimento e ao respeito às diferenças de grupos sociais específicos, bem como aquelas relacionadas às questões culturais. 
A quinta e última categoria, intitulada "Estratégias de luta", buscava identificar as estratégias de luta adotadas pelos distintos movimentos e formas de expressão da participação social na atualidade, com intuito de reconhecer e comparar as estratégias utilizadas no conjunto da América Latina ${ }^{7}$. Algumas das principais estratégias adotadas no contexto latino-americano, segundo Seoane ${ }^{17}$, referem-se às marchas, mobilizações, ocupações e bloqueio de estradas, embora existam também outras estratégias utilizadas.

Após a elaboração dessas categorias, optou-se por fazer a matriz de análise utilizando o sistema EPI-INFO, pois acreditava-se que esse sistema possibilitaria a adoção de uma padronização na aplicação e também facilitaria o trabalho em rede, já que havia pesquisadores de vários países da América Latina. Assim, o desenvolvimento dos trabalhos se daria de modo simultâneo e a distância. A seguir, apresentam-se algumas janelas do sistema criado, para exemplificar:

Figura 1. Modelo da Matriz de Análise da Participação Social ${ }^{7}$, codificada no sistema EPI-INFO

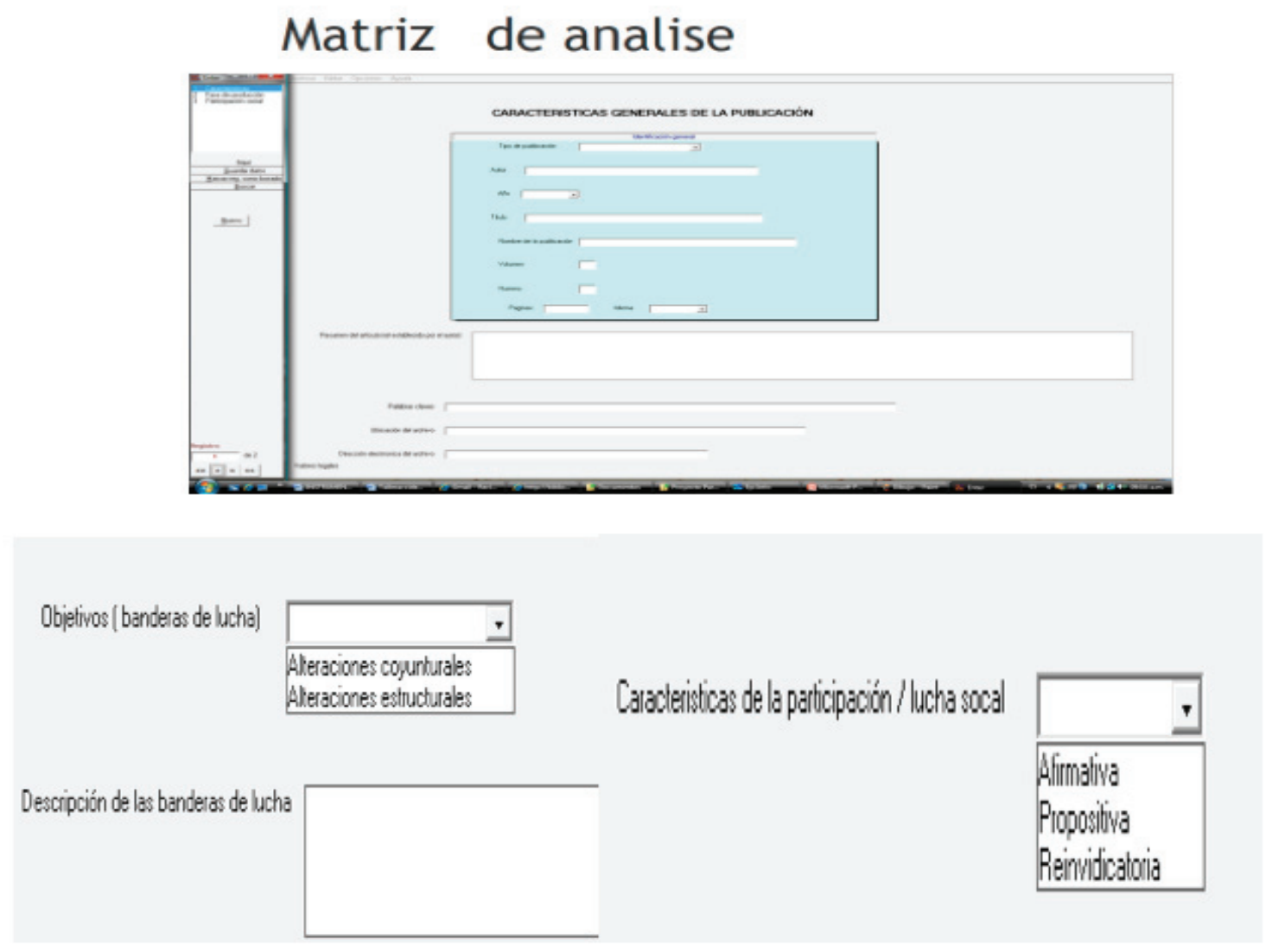

Cabe ressaltar que se trabalhava com o pressuposto de que a participação social carrega consigo três dimensões que se inter-relacionam: dimensão ideológica, dimensão política e dimensão epistemológica. Como tal, acreditava-se que as relações entre o conjunto de todas as categorias adotadas permitiria analisar as formas de participação social de um modo mais ampliado. A síntese 
das dimensões de análise encontra-se no quadro a seguir:

Figura 2. Matriz de Análise da Participação Social ${ }^{7}$

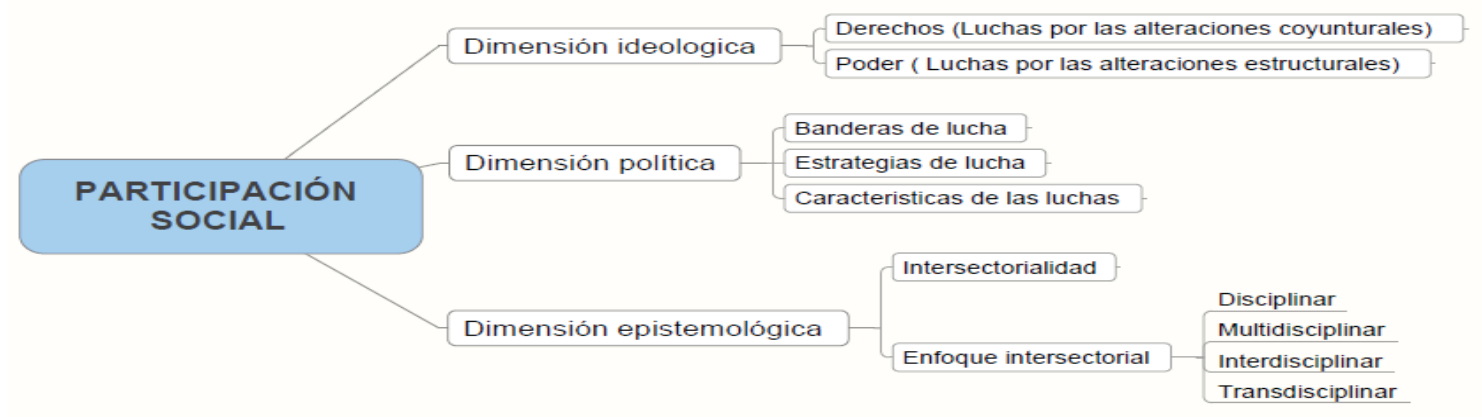

Essa primeira versão da matriz constituiu uma espécie de projeto piloto de sua aplicação e possibilitou a análise de uma amostra de 76 documentos que retratavam experiências de participação social no contexto da América Latina, cujos resultados foram apresentados em 2010, em seminário realizado pelo Community of Practice in Ecohealth - Toxics in Latin America and the Caribbean (CoPEH-TLAC), ente financiador da pesquisa.

Tendo em vista que não é o objetivo deste artigo discutir os resultados dessa pesquisa, importa aqui destacar que a matriz demonstrou aplicabilidade e possibilitou uma aproximação interessante do cenário existente das formas de participação social latino-americanas, mesmo que considerados os limites inerentes de toda pesquisa documental.

Cabe destacar que a qualidade da padronização da análise dos dados por meio da matriz, evidentemente, não se constituiu somente pela adoção do sistema EPI-INFO, mas, sobretudo, pelo profundo processo de discussão e construção teórica que antecedeu sua aplicação. Isso possibilitou um alinhamento do entendimento acerca das categorias adotadas, bem como a adoção de nomenclaturas padronizadas, utilizadas para definir e caracterizar as informações encontradas, viabilizando a redução da margem de erro relacionada às possíveis diferenças de interpretação dos dados no desenvolvimento da pesquisa. Ademais, realça-se que a matriz viabilizou análises qualitativas e quantitativas, uma vez que também é possível mensurar algumas categorias, desde que o alinhamento teórico e nomenclatura padrão anteriormente mencionados sejam bem alinhados.

No entanto, ao término da pesquisa, a avaliação do processo provocou reflexões interessantes, que apontavam para a necessidade de flexibilizar alguns conceitos e, consequentemente, realizar algumas alterações na matriz. Essa demanda adveio da constatação de que as realidades dos processos de participação encontradas nos documentos sinalizavam que nem sempre as categorias encontradas poderiam ser caracterizadas de forma binária.

As configurações das experiências de participação se mostravam mais complexas e a dinâmica 
social sinalizava, por exemplo, a impossibilidade de caracterizar todas as lutas necessariamente como estruturais ou conjunturais, posto que muitas delas continham em si esses dois elementos, simultaneamente. O mesmo acontecia com a questão das "Características da participação/Luta social", visto que muitas vezes as lutas empreendidas revelavam tanto elementos reivindicatórios como também propositivos e/ou afirmativos.

Apesar da necessidade de flexibilizar e fugir ao binário, todas as categorias adotadas se mostraram fundamentais para a compreensão da participação social e das formas de expressão dos movimentos. Ou seja, não se tratava da categoria em si, mas da rigidez conceitual que conduziu a opção dual.

Essas observações, muito mais do que meras questões operacionais da plataforma adotada, revelavam alguns limites dos conceitos a priori adotados e exigiam, simultaneamente, dois "movimentos": por um lado, o retorno à realidade concreta com a abertura necessária para, de fato, "ver" suas pluralidades e, por outro, o aprofundamento e busca de referenciais teóricos que auxiliassem a compreender o que a dinâmica social parecia sinalizar.

Ademais, ressalta-se que uma questão fundamental que emergiu da avaliação diz respeito à importância da construção, debate e pactuação prévia da pesquisa com os movimentos sociais e grupos sujeitos nela envolvidos, bem como a necessidade de incluir em seu desenvolvimento outros instrumentos capazes de trazer o "olhar" dos sujeitos.

\section{Processo de construção da Matriz de Análise - Segunda versão}

Assim, a construção da segunda versão da matriz inicia-se em 2011, vinculada à realização de uma pesquisa-ação intitulada "Resistência e violência no contexto dos conflitos socioambientais na Chapada do Apodi, Ceará", um estudo de pós-doutorado ${ }^{8}$, desenvolvido em cooperação entre a Universidade de Brasília (UnB) e a Universidade Federal do Ceará (UFCE). Ressalta-se que, no âmbito desse estudo, entende-se por "resistência" o conjunto dos processos de participação dos movimentos sociais e organizações envolvidos em todas as lutas de enfrentamento da situação de violência existentes na região.

Essa pesquisa previa a realização de uma fase documental e uma fase que envolvia o desenvolvimento de ações articuladas à pesquisa, cujos objetivos incluíam: a) analisar as formas de resistência e violência existentes na referida região, especialmente nos municípios de Quixeré e Limoeiro do Norte-CE, b) construir um acervo histórico advindo do material mapeado e analisado, visando disponibilizá-lo para o conjunto dos movimentos e fortalecer os processos de participação e lutas; c) criar o Memorial da Chapada, o qual abrigaria o acervo e constituiria um espaço sociocultural voltado para articulação e construção de redes, a troca de experiências de lutas, de organização, de resistências e de expressão das culturas locais. Destaca-se que a criação desse memorial seria realizada coletivamente com as comunidades locais, por meio de ações articuladas 
ao Projeto de Extensão Vidas Paralelas, vinculado à UnB.

Essa proposta de pesquisa foi previamente debatida e pactuada, em reunião realizada no município de Limoeiro do Norte, em dezembro de 2010, com o conjunto das organizações locais e pesquisadores da UFCE, que desenvolviam trabalhos na região há muitos anos. Além disso, a análise dos dados foi submetida à apreciação dos movimentos e grupos envolvidos no estudo.

Isso posto, considerando as potencialidades que a matriz de análise havia demonstrado e também as necessidades de alteração sinalizadas, optou-se, primeiramente, pela busca de novos referenciais teóricos que pudessem dar conta da complexidade que envolve a análise dos processos de participação social na conjuntura atual da sociedade e, como tal, contribuir para a realização deste estudo.

Desse modo, após realização de revisão teórica, optou-se por incorporar o marco teórico de Boaventura de Sousa Santos ${ }^{10,11}$, especialmente o conceito de intensidade democrática, visto que este poderia contribuir com o aprofundamento da referida análise. $\mathrm{O}$ autor sustenta que não há democracia de alta intensidade sem a democratização do direito, do poder e do saber. Nesse sentido, propõe uma forma de classificação da democracia, cuja intensidade democrática é definida pela existência de autoridade partilhada e do reconhecimento recíproco dos sujeitos enquanto sujeitos de direitos ${ }^{10,11}$.

A autoridade partilhada refere-se à partilha do poder, ou seja, à criação de oportunidades de acesso ao exercício do poder por novos atores sociais historicamente excluídos. Nesse sentido, a partilha do poder não se limita ao compartilhamento de informações, à consulta ou assessoria, mas refere-se, sobretudo, à capacidade de transformar relações assimétricas de poder, de tal forma que as práticas de participação possam ampliar o espectro das lutas e os resultados alcançados, favorecendo a ampliação dos direitos, do poder e dos saberes, uma vez que não há democratização das práticas sem a democratização dos saberes. A desvalorização e desqualificação do saber do outro é parte inerente dos processos antidemocráticos. ${ }^{10,11,19}$

Assim, a reciprocidade reconhecida é também condição para a alta intensidade democrática, uma vez que se trata do reconhecimento mútuo dos sujeitos enquanto sujeitos de direitos e enquanto sujeitos que carregam consigo saberes forjados no cotidiano das lutas. ${ }^{10}$ Desse modo, a reciprocidade reconhecida refere-se ao reconhecimento recíproco dos atores sociais que compartilham de processos e que, ao serem reconhecidos e ao reconhecerem, expressam, por sua vez, a abertura à inclusão de novos atores e, consequentemente, a ampliação da participação social e da representatividade das lutas empreendidas.

Dessa forma, as práticas de participação que sinalizem a presença e inclusão progressiva de diferentes atores sociais, para além de sugerir a partilha do poder, também poderiam indicar, a depender do contexto, a existência de representatividade e, como tal, de legitimidade, visto que 
quanto maior a participação, mais legítimo se torna o processo. Ademais, o reconhecimento recíproco é premissa para a construção de $\operatorname{consensos}^{10}$, pois ninguém consensua com alguém cuja existência não reconhece.

Considerando o exposto, ao fazer a relação entre o marco teórico e as categorias centrais existentes na primeira versão da matriz, encontraram-se muitos atravessamentos que sugeriam a capacidade delas expressarem, no plano concreto, a concepção elaborada por $\operatorname{Santos}^{10} \mathrm{e}$, como tal, analisar a intensidade democrática dos processos de participação, desde que consideradas as alterações já pontuadas na avaliação final daquela versão.

Buscou-se, então, a partir dos saberes acumulados na primeira matriz, reformular uma proposta mantendo-se as categorias centrais da primeira e reconstruindo as subcategorias. A síntese das categorias de análise adotadas na segunda versão da matriz e alinhadas com o marco teórico adotado encontra-se esquematizada na figura a seguir:

Figura 4. Matriz de Análise da Participação Social ${ }^{8}$
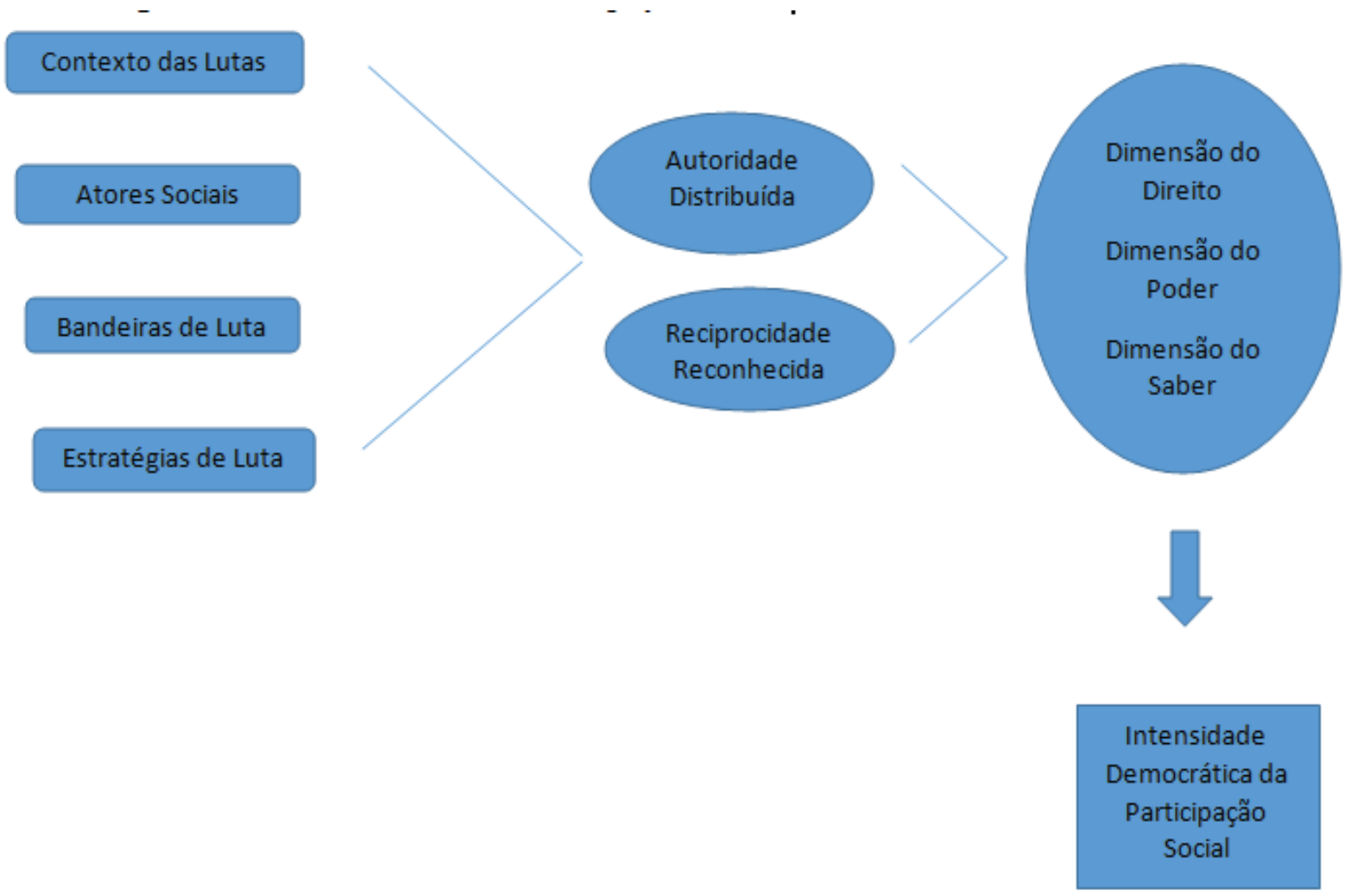

Dessa forma, acreditava-se que, a partir da compreensão do contexto e da identificação dos atores sociais presentes no decorrer do processo histórico, seria possível vislumbrar a capacidade dos processos de participação analisados no que tange à ampliação e à inclusão de novos sujeitos no exercício do poder, bem como a capacidade de articulação política e, como tal, expressar a 
autoridade distribuída e a reciprocidade reconhecida.

Além disso, havia o entendimento de que o conhecimento das bandeiras de luta também sinalizaria o compartilhamento do poder, uma vez que elas expressam quais são os direitos reivindicados e, por consequência, para além da dimensão dos direitos, evidenciam a capacidade de disputa pelo poder com vistas à sua redistribuição.

No entanto, o conhecimento das estratégias de luta permitiria apreender em que medida elas questionavam e/ou atuavam sobre as estruturas de poder instituído e revelar, de certo modo, se as ações adotadas incluíam também estratégias de ações políticas diretas - sejam elas marchas, ocupações, entre outras - como também de produção e compartilhamento dos saberes construídos no âmbito dos processos de luta dos movimentos e grupos envolvidos.

Ademais, a análise das estratégias de luta, em conjunto com as demais categorias, também permitiria compreender a capacidade de articulação política e o âmbito das lutas, favorecendo a leitura sobre as condições de democratização do poder, do direito e do saber e, consequentemente, a análise da intensidade democrática da participação social.

Essas categorias centrais foram transpostas para o Excel, com intuito de viabilizar sua aplicação de forma padronizada e sistemática. Desse modo, em comparação com a primeira versão da matriz, ressalta-se que foi abandonada a utilização do sistema EPI-INFO e todas as categorias passaram a ser descritivas. Ademais, foi adotado um sistema de cores para as subcategorizações, com intuito de facilitar a visualização e a análise do conjunto dos dados, conforme esquematizado na figura a seguir. É importante pontuar que a categoria "Violência/Violação dos direitos" não é objeto de discussão deste artigo, uma vez que foi incluída especificamente para alcançar um dos objetivos da referida pesquisa. 
Figura 5. Modelo da Matriz de Análise da Participação Social ${ }^{8}$, codificada no software Excel

\begin{tabular}{|c|c|c|c|c|c|c|c|c|c|c|}
\hline $\begin{array}{l}\text { Contexto sócio- } \\
\text { histórice }^{0} 1\end{array}$ & $\begin{array}{c}\text { De que luta } \\
\text { o documento } \\
\text { retrata? }^{2}\end{array}$ & $\begin{array}{l}\text { Que violência } \\
\text { o documento } \\
\text { retrata? }\end{array}$ & $\begin{array}{l}\text { Atores } \\
\text { sociais }\end{array}$ & $\begin{array}{c}\text { Mov. } \\
\text { sociais }\end{array}$ & Univ. & Estado & $\begin{array}{l}\text { Estratégias } \\
\text { de luta }^{4}\end{array}$ & $\begin{array}{l}\text { Ação } \\
\text { politica }\end{array}$ & $\begin{array}{l}\text { Produção de } \\
\text { Conhecimento }\end{array}$ & $\begin{array}{c}\text { Ação } \\
\text { Institucional }\end{array}$ \\
\hline 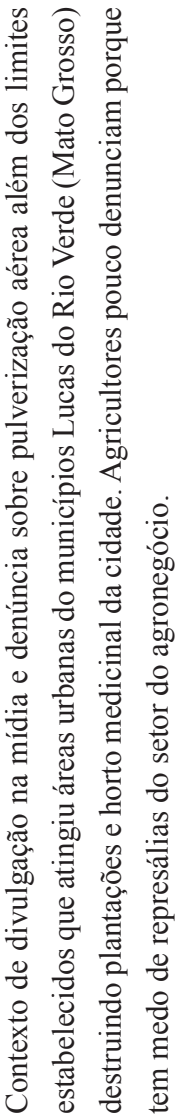 & 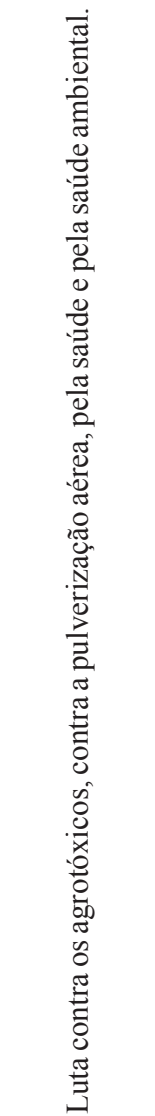 & 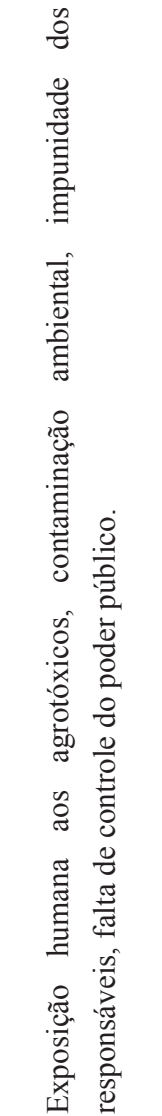 & 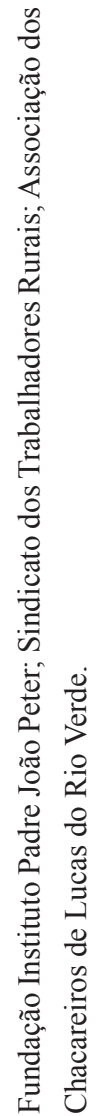 & & & & 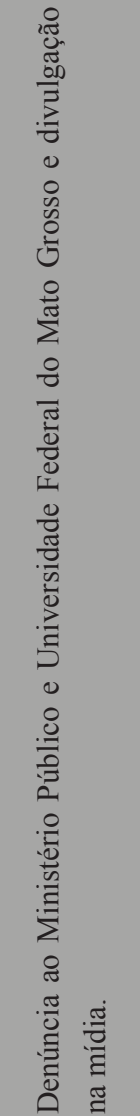 & & & \\
\hline
\end{tabular}

Notas: ( $\left.{ }^{1}\right)$ Fato correlacionado com a linha do Tempo/Corresponde ao período histórico da luta. $\left({ }^{2}\right)$ Bandeiras de luta. $\left({ }^{3}\right)$ Que formas de organização e de participação o documento retrata. (4) Estratégias ou tipo de ações desses atores sociais.

Tendo em vista que a adoção dessa matriz inclui um processo prévio de catalogação e classificação dos documentos, torna-se possível cruzar as informações ou mesmo agregar todas em uma única planilha, de tal forma que seja possível analisar, por exemplo, quais atores ou estratégias estão mais presentes em cada período histórico, propiciando análise do percurso da participação social estudada.

Nota-se que a categoria "Atores Sociais" foi subcategorizada em: a) Movimentos sociais, b) Universidade e c) Estado. Embora a universidade faça parte do aparelho do Estado, entende-se que sua autonomia e seu papel social lhe conferem profundas diferenças no que tange às relações que ela é capaz de estabelecer com o conjunto da sociedade civil e dos movimentos sociais. Além disso, buscava-se, com essa subcategorização, identificar em que medida a articulação política e o diálogo entre os saberes advindos das universidades e dos movimentos sociais vinha se concretizando, uma vez que isso contribuiria para a compreensão acerca da democratização dos saberes. 
As "Estratégias de luta" também foram subcategorizadas em: a) Ações políticas; b) Ações relacionadas à produção de conhecimento e c) Ações institucionais. Mesmo correndo o risco de parecer mecanicista, essa categorização foi adotada com intuito de colaborar com a análise da democratização das três dimensões em questão - direito, poder e saber - posto que as estratégias de participação social apresentam finalidades distintas e nem sempre atuam simultaneamente sobre os três campos, podendo ora incidir mais sobre um, ora sobre outro. Desse modo, no âmbito desta proposta, as Ações políticas referiam-se a todas aquelas voltadas, direta ou indiretamente, ao enfrentamento dos conflitos e a luta por direitos, que não necessariamente apresentavam encaminhamentos institucionais, ou seja, não obrigatoriamente adentravam a esfera do Estado.

No entanto, as Ações institucionais relacionavam-se às ações nas quais necessariamente existiam encaminhamentos direcionados às instituições governamentais competentes - via requerimentos, cartas, abaixo-assinados ou audiências públicas, para citar algumas - visando à exigência de providências e à garantia dos direitos cabíveis, bem como as ações cuja iniciativa fosse do Estado.

Quanto às Ações relacionadas à produção do conhecimento, referiam-se a todas as ações cujo objetivo, processo ou produto fosse a reflexão, o debate, o aprofundamento do conhecimento e/ou a produção de materiais didáticos e/ou políticos sobre as questões propostas e que permeassem as problemáticas presentes na região do estudo. Nesse caso, incluíam a organização e realização de seminários, congressos, produção de materiais realizados no âmbito dos movimentos sociais e/ou universidades, pesquisas, entre outros.

Essa matriz foi utilizada no estudo mencionado e possibilitou a análise de 217 documentos, com recorte histórico entre 2008 e 2010, tendo como fonte de informações os documentos advindos do acervo construído pelo Grupo Tramas, vinculado à Universidade Federal do Ceará (UFCE), e outras sete fontes de dados, oriundas especialmente dos movimentos sociais, meios de comunicação locais e alguns órgãos governamentais, tais como: Ministério Público Federal, Ministério Público Estadual e Delegacia de Polícia de Limoeiro do Norte.

Os processos analisados indicaram alta intensidade democrática, destacando-se como principais bandeiras: as lutas contra os agrotóxicos, a luta contra o agronegócio e a luta por um modelo de desenvolvimento justo e sustentável, pautado na agroecologia. Além disso, os dados evidenciaram que houve um esforço de ampliação das bases sociais e políticas envolvidas na situação de conflito e que, aos poucos, os sujeitos coletivos locais envolvidos foram articulando-se com outros movimentos e organizações, lançando as sementes do que viria a tornar-se, posteriormente, um movimento social dedicado às lutas específicas na região, intitulado "M21". 8

Os dados sinalizaram também avanços na construção de estratégias conjuntas com movimentos e organizações de amplitude nacional e internacional - tais como o Movimento dos Trabalhadores Rurais Sem Terra (MST), a Via Campesina, a Rede Brasileira de Justiça Ambiental (RBJA) e a Articulação Nacional de Agroecologia (ANA) - especialmente no que tange ao desenvolvimento 
de ações como a Campanha Permanente Contra os Agrotóxicos e Pela Vida e aos debates nacionais sobre questões vinculadas às políticas de saúde ambiental e saúde do trabalhador, evidenciando a ampliação das lutas e assinalando a existência de um trânsito dos limites locais em direção ao âmbito nacional e latinoamericano. ${ }^{8}$

Os resultados aprofundados dessa pesquisa são objeto de outro artigo, importa aqui mencionar que a matriz demonstrou aplicabilidade e possibilitou a análise da intensidade democrática dos processos de participação na região da Chapada do Apodi-CE. Entretanto, a avaliação da aplicação da segunda versão da matriz evidenciou algumas questões importantes. A primeira delas reitera as considerações assinaladas na avaliação da primeira versão e refere-se aos limites existentes em todo o estudo documental e, como tal, a importância da inclusão de outros instrumentos, processos e/ou mecanismos que viabilizem a escuta da "voz dos sujeitos" e movimentos que empreendem os processos de participação social.

A segunda questão relaciona-se à denominação adotada em uma subcategoria das Estratégias de luta, precisamente a subcategoria intitulada "Ações políticas". Após a avaliação, concluiu-se que a denominação deveria ser redefinida, pois dá margem a interpretações equivocadas no sentido de supor que, no âmbito desta matriz, não se considera as demais ações - Ações institucionais e Ações de compartilhamento de saberes - como ações políticas. Evidentemente, não se trata disso, mas tão somente de uma nomenclatura que buscava contemplar em seu bojo as conhecidas "ações de massa", expressão familiar ao conjunto da esquerda no Brasil e que historicamente são adotadas para reivindicar direitos.

Por fim, observando as categorias centrais da matriz (Contexto/Atores sociais/Bandeiras de luta/ Estratégias de luta), existentes desde a primeira versão, assinala-se que elas parecem constituir elementos que conferem potencialidade e flexibilidade suficientes para analisar processos de participação e atuação dos movimentos sociais a partir de distintos referenciais teóricos.

\section{CONSIDERAÇÕES FINAIS}

A Matriz de Análise discutida neste artigo evidencia um longo processo de construção e reflexão que envolveu avanços e recuos, idas e vindas e, sobretudo, muitos questionamentos. No entanto, ela representa uma experiência de aproximação do referencial teórico de Santos ${ }^{10,11}$, no sentido de transpor para o real elementos importantes para a compreensão dos processos de participação e atuação dos movimentos sociais.

A primeira pesquisa, realizada no âmbito da América Latina, constituiu o alicerce da matriz, uma vez que propôs as categorias centrais que demonstraram relevância nos processos de análise, motivo pelo qual foram mantidas na segunda versão e permanecem sendo utilizadas até o presente momento. Entretanto, a avaliação do processo de aplicação da primeira versão da Matriz assinalou questões fundamentais: a necessidade de retornar ao campo empírico, a necessidade de aprofundar 
o diálogo com os movimentos sociais e a importância de ampliar os referenciais teóricos.

Todas essas questões foram, em certa medida, amadurecidas na segunda experiência. A incorporação do referencial de Santos ${ }^{10,11}$ foi um dos caminhos escolhidos como desdobramento das inquietações advindas da primeira pesquisa e conduziu à reformulação da proposta, à construção de novas subcategorias e à consequente transição de um sistema predominantemente binário e, portanto, inflexível, para um modelo aberto e com maior capacidade analítica.

Acredita-se que a segunda versão da matriz avança no sentido de expressar em seu conjunto as relações estabelecidas entre as concepções teóricas de Santos ${ }^{10,11}$ e as categorias e subcategorias criadas, sinalizando potencialidades e aplicabilidade no que tange à análise da intensidade democrática da participação e atuação dos movimentos sociais.

No entanto, cabe destacar que toda matriz carrega consigo o risco do enquadramento e, como tal, precisa ser permanentemente adaptada a partir da dinâmica da realidade, precisa "ser viva" para que possa, de fato, contribuir com a "leitura do mundo", afinal, como dizia Freire ${ }^{18}$, "ela precede a leitura da palavra".

\section{REFERÊNCIAS}

1 Gohn MG. Novas Teorias dos Movimentos Sociais. São Paulo: Loyola; 2008. 166 p.

2 Gohn MG. Os Sem Terra, ONGs e Cidadania. São Paulo: Cortez; 2003. 172 p.

3 Gohn MG. Movimentos Sociais no Início do Século XXI: antigos e novos atores sociais. Petrópolis: Vozes; 2003. 143 p.

4 Scherer-Warren I. Redes de Movimentos Sociais. São Paulo: Loyola; 2005. 143 p.

5 Carvalho AI. Conselhos de Saúde no Brasil: participação cidadã e controle social. Rio de Janeiro: FASE/IBAM, 1995. 135 p.

6 Severo DO. O Movimento dos Trabalhadores Rurais Sem Terra e o Controle Social do SUS: concepção do Coletivo Nacional de Saúde [dissertação]. [Florianópolis]: Universidade Federal de Santa Catarina; 2008. 107 p.

7 Hoefel MGL, Severo DO, Mussi M, Benavides J, Braga LQV, Pereira MF. Relatório de Pesquisa Políticas, Participación Social y Actores Sociales. Pesquisa financiada pelo COPEHTLAC. Universidade de Brasília, 2010.

8 Hoefel MGL, Severo DO, Pereira MF, Braga LQV, Peixoto J.; Resistência e Violência no contexto dos Conflitos Socioambientais na Chapada do Apodi/Ceará [relatório de pesquisa]. [Fortaleza]: Universidade Federal do Ceará, 2011.

// Tempus, actas de saúde colet, Brasília, 8(2), 27-45, jun, 2014. 
9 Gomez CM, Minayo MC. Enfoque Ecossistêmico de Saúde: uma estratégia transdisciplinar. Interfaceshs. 2006;1:2-19.

10 Santos BS. A filosofia à venda, a douta ignorância e a aposta de Pascal. Revista Crítica de Ciências Sociais. 2008;80:11-43.

11 Santos BS. Democratizar a Democracia: os caminhos da democracia participativa. In: Santos BS, organizador. Reinventar a Emancipação Social. Para Novos Manifestos. Rio de Janeiro: Civilização Brasileira; 2002.

12 Minayo MCS. Enfoque ecossistêmico de saúde e qualidade de vida. In: Minayo MCS, Miranda AC, organizadores. Saúde e ambiente sustentável: estreitando nós. Rio de Janeiro: Editora Fiocruz; 2002. p. 173-89.

13 Gohn MG. Teoria dos Movimentos Sociais: paradigmas clássicos e contemporâneos. São Paulo: Loyola; 2008. 383 p.

14 Mirza CA. Los Casos Examinados: movimientos sociales y sistemas de partidos en Argentina, Brasil, Chile, Ecuador, Paraguay, Venezuela y Uruguay. In: Mirza CA, organizador. Movimientos sociales y sistemas políticos en América Latina. Buenos Aires: Clacso; 2006. p. 67-172.

15 Izaguirre I. Algunos ejes teórico-metodológicos en el estudio del conflito social. In: Seoane, J, organizador. Movimientos Sociales y Conflicto en América Latina. Buenos Aires: Clacso; 2004.

16 Quevedo J, Iokoi ZMG, organizadores. Movimentos Sociais na América Latina: desafios teóricos em tempos de globalização. Santa Maria: MILA, CCSH; 2007. 326 p.

17 Seoane J. Movimientos Sociales y Recursos Naturales em América Latina: resistencias al neoliberalismo, configuración de alternativas. Sociedade e Estado. 2006;21(1):85-107.

18 Freire P. A importância do ato de ler: em três artigos que se completam. 15 a ed. São Paulo: Cortez, Autores Associados; 1989.

Artigo apresentado em 06/04/14

Artigo aprovado em 14/06/14

Artigo publicado no sistema em 29/06/14 